\title{
Application of a novel shape-memory alloy concentrator in displaced olecranon fractures: a report of the technique and mid-term clinical results
}

Demeng Xia ${ }^{1,2+}$, Panyu Zhou ${ }^{1+}$, Lei $\mathrm{Li}^{1}$, Yan Xia ${ }^{1}$, Zichen Hao ${ }^{1}$, Yuntong Zhang ${ }^{1 *}$ and Shuogui Xu ${ }^{1 *}$ (D)

\begin{abstract}
Purpose: Olecranon fracture is a common upper limb fracture, and several surgical approaches have been advocated for its fixation. To overcome the complications associated with common techniques, we present a novel shape-memory alloy concentrator, an alternative for tension band compression, to fix olecranon fracture.

Methods: Fifty-seven patients (26 men and 31 women) with olecranon fracture, with a mean age of 45 years, were included in this study. Each patient had undergone open reduction and internal fixation using the Nitinol (Ni-Ti) arched shape-memory connector (ASC). The clinical assessments were performed using the Disability of the Arm, Shoulder, and Hand (DASH) questionnaire and the Mayo Elbow Performance (MEP) score, which were both recorded at the final follow-up visit.

Results: The patients were followed up for 44 months on average (range, 31 to 56 months). No patients were lost to follow-up, and all of the olecranon fractures healed in an average of 15 weeks (range, 10 to 34 weeks). The mean DASH score was 8.6 (range, 0 to 32.4), and the mean MEP score was 92.5 (range, 74 to 100). Nine patients showed postoperative complications: prominent hardware (2), infection (1), loss of the range of functional motion (5), and heterotopic ossification (1).

Conclusion: The ASC may serve as a favorable device for multi-fragmented and comminuted fractures with rare hardware irritation and may also provide continuous concentrative compression to accelerate osseous healing, thereby aiding the restoration and permitting an early rehabilitation with a low incidence of postoperative complications.
\end{abstract}

Keywords: Olecranon fractures, Shape-memory alloy concentrator, Technique

\footnotetext{
*Correspondence: mone1030@126.com; 18516116672@163.com ${ }^{\dagger}$ Demeng Xia and Panyu Zhou contributed equally to this work. 'Department of Emergency, Changhai Hospital, the Naval Medical University, No.168, Changhai St, Shanghai 200433, People's Republic of China Full list of author information is available at the end of the article
}

(c) The Author(s). 2020 Open Access This article is licensed under a Creative Commons Attribution 4.0 International License, which permits use, sharing, adaptation, distribution and reproduction in any medium or format, as long as you give appropriate credit to the original author(s) and the source, provide a link to the Creative Commons licence, and indicate if changes were made. The images or other third party material in this article are included in the article's Creative Commons licence, unless indicated otherwise in a credit line to the material. If material is not included in the article's Creative Commons licence and your intended use is not permitted by statutory regulation or exceeds the permitted use, you will need to obtain permission directly from the copyright holder. To view a copy of this licence, visit http://creativecommons.org/licenses/by/4.0/. The Creative Commons Public Domain Dedication waiver (http://creativecommons.org/publicdomain/zero/1.0/) applies to the data made available in this article, unless otherwise stated in a credit line to the data. 


\section{Introduction}

Olecranon fractures are among the most common injuries, accounting for approximately $1 \%$ of all skeletal injuries and up to $10 \%$ of fractures of the elbow joint [1-3]. Based on a literature review, only $5-7 \%$ of patients who had non-displaced or displaced fractures required manipulative reduction and external fixation; however, more than 93\% of fractures that included fragment dislocation required open reduction and internal fixations [4, 5]. It has been reported that displaced transverse fractures of the olecranon are the most common fractures occurring in the elbow in adults that require operative intervention [6]. Although tension band wiring (TBW) is a well-considered standard to treat olecranon fractures [7], the approach, due to back-out or proximal migration of the longitudinal wires, stimulates soft tissues and may be a source of discomfort for the patients $[8,9]$. On average, the rates of removal following TBW are reported to be as high as $80 \%$ [1]. Additionally, the tension band wiring method does not apply to all types of fractures [10]. Plate fixation (PF) can overcome the main shortcoming of TBW and is mainly reserved for comminuted fractures or distal fractures, showing a biomechanical advantage over tensionband wiring and a reported lower rate of hardware removal [11]. Nevertheless, extreme bending stresses at the proximal part of the ulna can lead to fatigue failure of internal fixation devices occasionally [12]. Therefore, a novel surgical method to treat olecranon fractures has always been explored.

First appearing in the $1960 \mathrm{~s}$, nitinol (Ni-Ti) shapememory alloys were approved by the FDA for clinical application in 1990. These alloys seem to open a whole new range of applications due to their shape-memory effect, corrosion resistance, wear resistance, super-elasticity, and favorable histocompatibility [13-16]. This innovative material has been widely used in the neurosurgery [13], cardiovascular [17], and orthopedic fields [18]. To further utilize the special mechanical behavior of the shapememory material, we designed a shape-memory alloy concentrator called the $\mathrm{Ni}-\mathrm{Ti}$ arched shape-memory connector (ASC), which has been applied for internal fixation since the 1990s [19-21]. The current study aimed to introduce the peculiarity of the ASC and retrospectively evaluate the efficacy and clinical outcomes of the ASC in the treatment of olecranon fractures.

\section{Materials and methods}

One-hundred and forty-five patients with olecranon fractures, who were admitted to the Trauma and Emergency Department of Changhai Hospital, Naval Medical University, between December 2010 and December 2017, were recruited for this study. The Committee on Ethics of Biomedicine Research of Changhai Hospital authorized all the procedures. The selection criteria included patients with Mayo type II and type III olecranon fractures. The exclusion criteria included patients with (1) Mayo type I olecranon fracture, (2) non-traumatic fracture, (3) nonunion olecranon fracture, (4) an age less than 18 years at the time of injury, and (5) psychological and social conditions with poor compliance. The flowchart representing the selection and exclusion for the analysis of ASC for olecranon fractures is shown in Fig. 1.

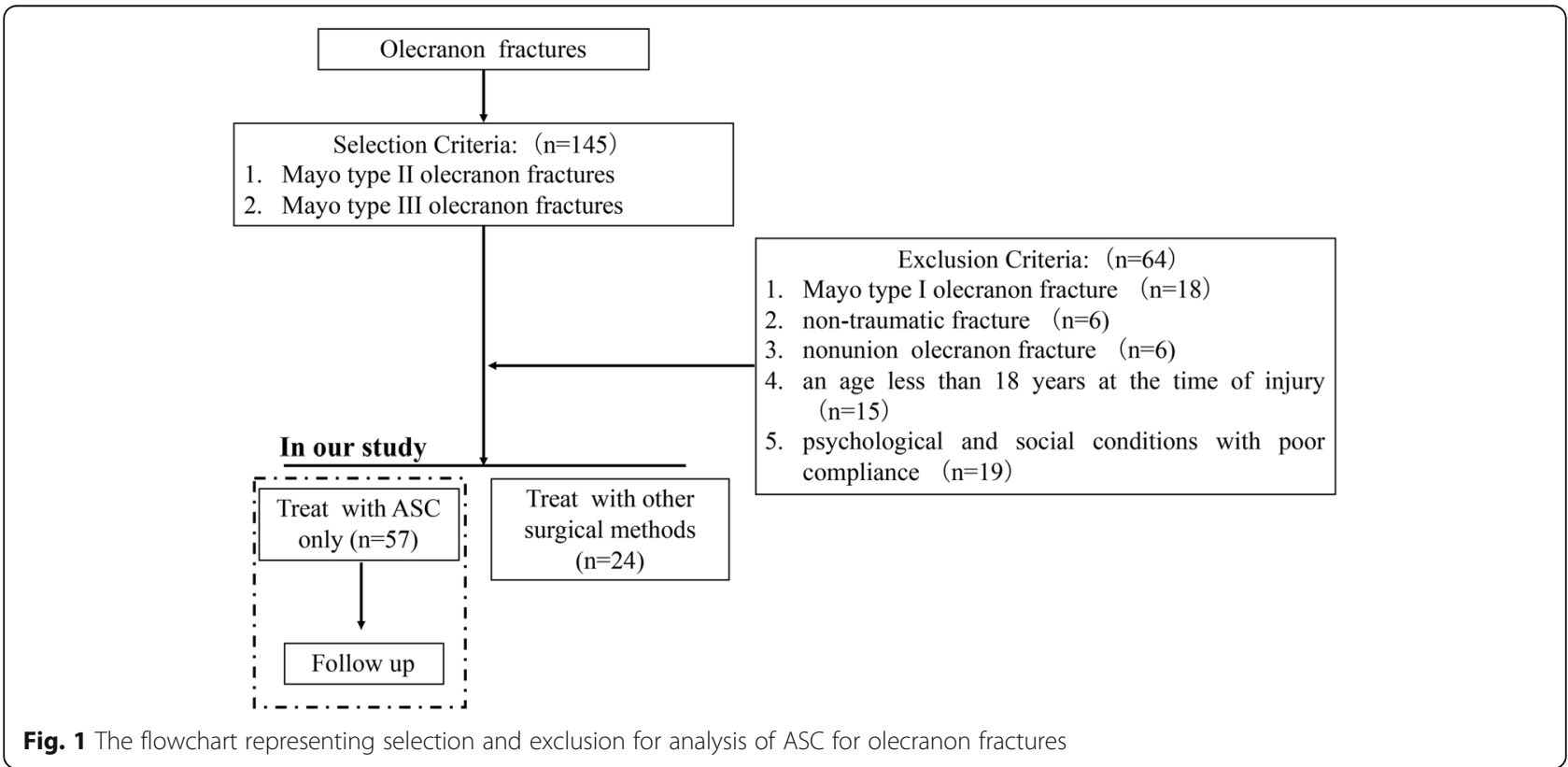




\section{Structure and working principles of the ASC}

The ASC device (Huzhou Swan Biological Memory Medical Devices Co., Ltd., Zhejiang, China) is designed based on the anatomical structure of the olecranon and manufactured with 2-mm-thick Ti-Ni shape-memory alloy. The ASC comprises of 50-53\% nickel, with the remainder comprising titanium. The device has compression arms that are connected to the waist. The transition temperature is set at $33^{\circ} \mathrm{C} \pm 2{ }^{\circ} \mathrm{C}$ with one-way heat treatment. The device exhibits a unilateral memory effect and a shape change quantity of $8 \%$. The ASC is malleable at lower temperatures (martensite phase); thus, it is placed in $0-4{ }^{\circ} \mathrm{C}$ ice water for cooling before implantation. When the fixation is completed, $40-50^{\circ} \mathrm{C}$ water was used to warm the device to stimulate its mechanical memory functions (austenite phase), providing a continuous lateral compressive force. The shape change process of the ASC is shown in video 1 as supporting materials

\section{Surgical procedure}

A longitudinal posterior skin incision was made to the exposure of the olecranon. Excessive exposure of the dorsal surface of the proximal ulna was not recommended only when the comminuted fracture lines were involved. If any articular fragment was impacted, it was elevated, and any coronoid fracture was reduced and temporarily fixed to the ulna with Kirschner wires. After clearance of the bone debris and soft tissues and internal fixation of the olecranon fracture, the ASC was preincubated previously in ice water $\left(0-4{ }^{\circ} \mathrm{C}\right)$ to allow the plastic deformation of the Ni-Ti alloy. Next, the arm was unfolded using needle forceps, and two holes were drilled on either side of the fracture lines to embed the arms of the ASC, where the ligature between the two holes was as perpendicular to the fracture line as possible. According to the actual condition of the ulnar fracture, two or more additional ASCs were required for stable fixation. After the fracture sites were reduced, the ASC was embedded into the bone and reheated in warm water (40$50{ }^{\circ} \mathrm{C}$ ) to stimulate the reversion of the arms and waist back to their original shapes, which correspondingly generated a continuous compression force on the fracture line. Based on the above procedures, the memory alloy created fixation by maintaining the bone block in a system driven by temperature. The application process of the ASC is briefly illustrated in Fig. 2, and detailed introduction of the structure and working principles can be reviewed in previous reports [22, 23]. The subcutaneous tissues and skin were closed in the usual way of

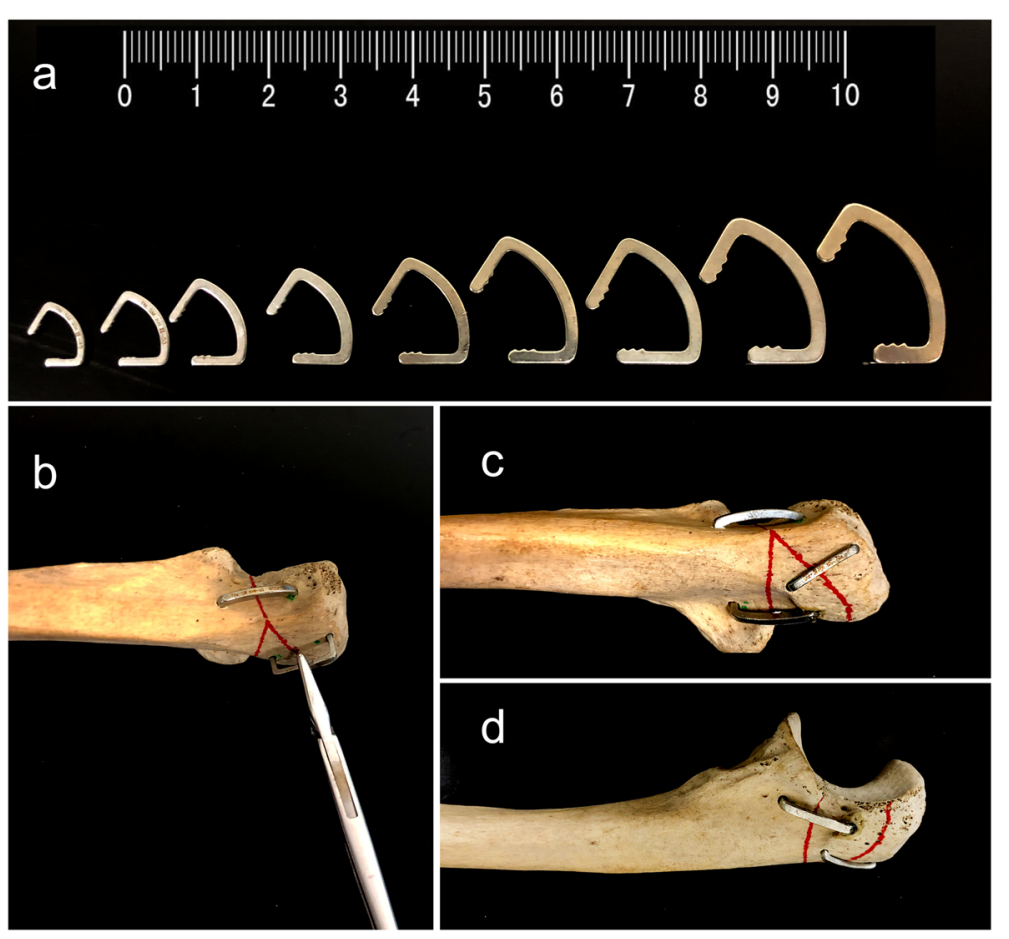

Fig. 2 Different size of arched shape-memory connectors which can be applied on different types of fractures, choose the most suitable arched shape-memory connector (a). Drill two holes on both sides of the fracture line and place the arched shape-memory connector vertically according to the fracture line (b). Finally, embed the compression arms and reheated in warm water to stimulate the reversion of the arms and waist back to their original shapes; several arched shape-memory connectors are used for the stable fixation of fractures and diagrams of the arched shape-memory connector fixation on specimen in AP (c) and lateral (d) views 
surgery. Finally, a removable plaster stand was used to hold the elbows bent to $90^{\circ}$. If pain could be tolerated, the patient was encouraged to make active movements of the fingers and isometric contraction of the upper arm muscles. From the second day after the operation, active assistive exercise was gradually performed. At the same time, the patient was required to remove the arm from the plaster support, and the flexion and extension of the elbow were performed appropriately several times a day, gradually increasing the amplitude and range of the movement.

\section{Clinical outcomes evaluation}

The follow-ups were performed, and radiographic assessments were routinely performed at 1 month, 2 months, 3 months, 6 months, and 1 year and at a half-year or 1-year interval thereafter. The Disability of the Arm, Shoulder and Hand (DASH) questionnaire was used to evaluate impairments and activity limitations [24]. The Mayo Elbow Performance (MEP) score was also used as a comprehensive assessment considering the following four factors: pain, ulnohumeral motion, stability, and the ability to perform five functional tasks [24]. According to the previous report [25], the functional range of movement in the operated elbow was flexion $\geq 128^{\circ}$, extension $\geq 116^{\circ}$, and pronation and supination $\geq 72^{\circ}$; when any one of the elbow joints does not meet these 4 criteria, we considered it a loss of the functional range of motion. All the clinical assessments used in this study were performed by independent observers, and the results were independently interpreted by two authors.

\section{Results}

Of the total number of patients recruited for the study, 57 patients (26 men and 31 women) were eligible for inclusion in the research. The mean age of the patients was 45 years (range, 22-60 years). The main cause of fracture in $23(40.4 \%)$ of the patients was a fall. Meanwhile, the mechanism of injury in 19 (30.3\%) of the patients was a vehicular accident, whereas that in the remaining $15(26.3 \%)$ patients was a sports-related injury. The classification of all of the fractures from the patients was made based on the basis of the Mayo classification system, which distinguishes the following three factors that directly influence on treatment: fracture displacement, presence of comminution, and ulnohumeral stability [2]. In this study, 14 fractures $(24.6 \%)$ were type IIA, 14 fractures (24.6\%) were type IIB, 20 fractures (35.1\%) were type IIIA, and 9 fractures (15\%) were type IIIB. The demographics of olecranon fracture patients are shown in Table 1.

None of the fractures were open injuries. Thirty patients sustained other fractures at the time of olecranon injury, including three radial head fractures, three coronoid
Table 1 Demographics of olecranon fracture patients

\begin{tabular}{ll}
\hline Patients, $\boldsymbol{n}$ & $\mathbf{5 7}$ \\
\hline Age, years(range) & $45(22-60)$ \\
Sex, $n$ (\%) & 26 \\
Male & 31 \\
$\quad$ Female & \\
Mechanism of injury, $n$ (\%) & 23 \\
Fall onto elbow & 19 \\
Vehicular accidents & 15 \\
Sports injury & \\
Mayo classification & 14 \\
Type IIA & 14 \\
Type IIB & 20 \\
Type IIIA & 9 \\
Type IIIB & $1.9(3.2 ; 1-7)$ \\
Mean time to surgery, days (SD; range) & 68 (11.2; 35-133) \\
Mean operative time, mins (SD; range)
\end{tabular}

fractures, three calcaneal fractures, two pelvic fractures, two femoral fractures, and one tibial fracture. The mean duration of the operation was 1.9 days (range, 1 to 7 days) from the time of the initial injury (Table 1). The mean duration of the operative time spent dealing with the olecranon fracture was $68 \mathrm{~min}$ (range, 35 to $133 \mathrm{~min}$ ).

The postoperative radiographic measurements demonstrated an anatomical or nearly anatomical reduction of olecranon fractures in all patients (Figs. 3, 4, 5). None of the patients showed a postoperative articular gap of more than $2 \mathrm{~mm}$. The patients were followed up for 44 months on average (range, 31 to 56 months). No loss of anatomical reduction was observed in the patients, and all of the olecranon fractures healed after an average of 15 weeks (range, 10 to 34 weeks). At the most recent follow-up, the mean DASH score was 8.6 (range, 0 to 32.4), and the mean MEP score was 92.5 (range, 74 to 100). Nine patients had postoperative complications: prominent hardware (2), infection (1), loss of range of functional motion (5), and heterotopic ossification (1), and it was obvious that the most common complication was the loss of functional motion. Mild pain due to prominent hardware was reported in one patient who had two ASCs implanted at the dorsal of the olecranon due to the presence of the proximal pole fracture line, but it was well-tolerated. Furthermore, none of the patients requested metal removal during the follow-up period. The preoperative and final follow-up clinical outcomes are presented in Table 2.

\section{Discussion}

Fifty-seven patients were followed up, and all of the olecranon fractures healed in an average of 15 weeks in 

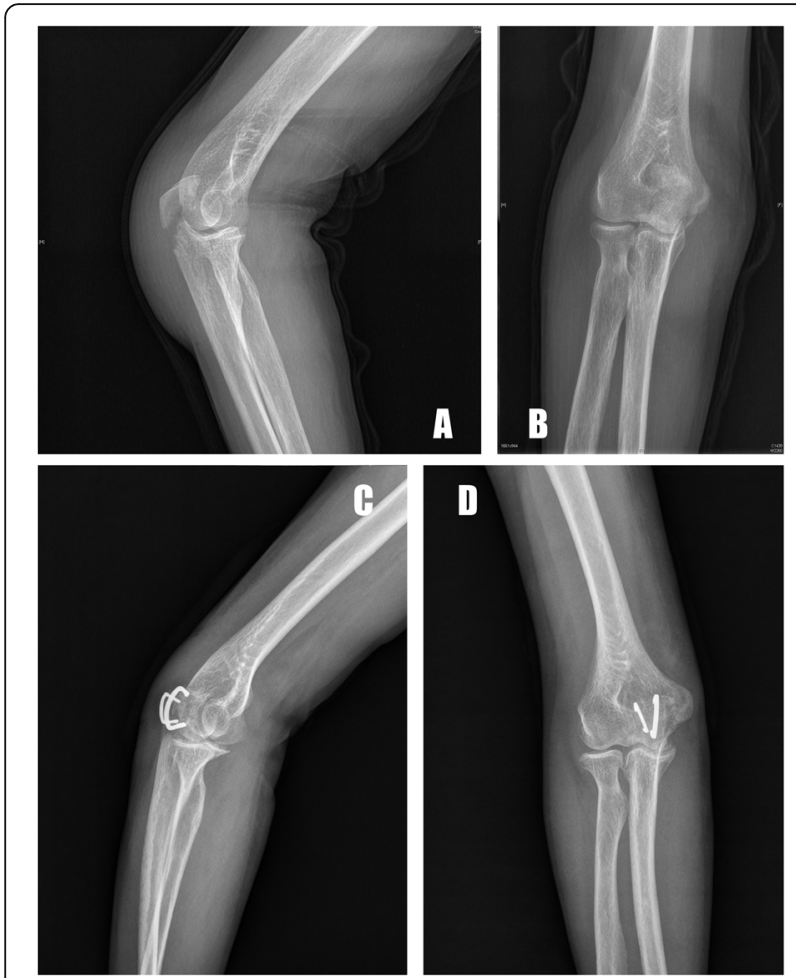

Fig. 3 A 54-year-old male patient with comminuted olecranon fracture caused by a vehicular accident $(\mathbf{a}, \mathbf{b})$. The comminuted fragments were reduced and fixed anatomically with two ACS. Seven months after surgery, the radiographs showed a healed fracture with metallic implants and no obvious gap or step-off along the joint surface $(\mathbf{c}, \mathbf{d})$

our study. The mean DASH score and the MEP scores were favorable. However, 9 patients had postoperative complications, the most common being the loss of functional motion.

The aims of treatment are to provide absolute stability of the fracture and to restore the joint surface to allow range-of-motion exercises in the early postoperative period [26]. Compared with the rare nondisplaced fractures with a displacement of less than $2 \mathrm{~mm}$, for which non-operative treatment is recommended [27], open reduction and internal fixation are recommended for most olecranon fractures to avoid complications such as fracture nonunion, joint stiffness, traumatic arthritis, ossifying muscle inflammation, and joint adhesions [28]. In clinical practice, various internal fixations can be applied to reconstruct the anatomical structure and recover the elbow function, such as figure-eight steel wire fixation, anatomical plate, K-wire tension band, hollow nail plus tension, and $1 / 3$ tube type plate $[19,29,30]$, the most frequently used techniques being tension band wiring (TBW) and plate fixation (PF) $[28,31]$.

The technical advantage of TBW is that this method can convert tension at the fracture site, which is
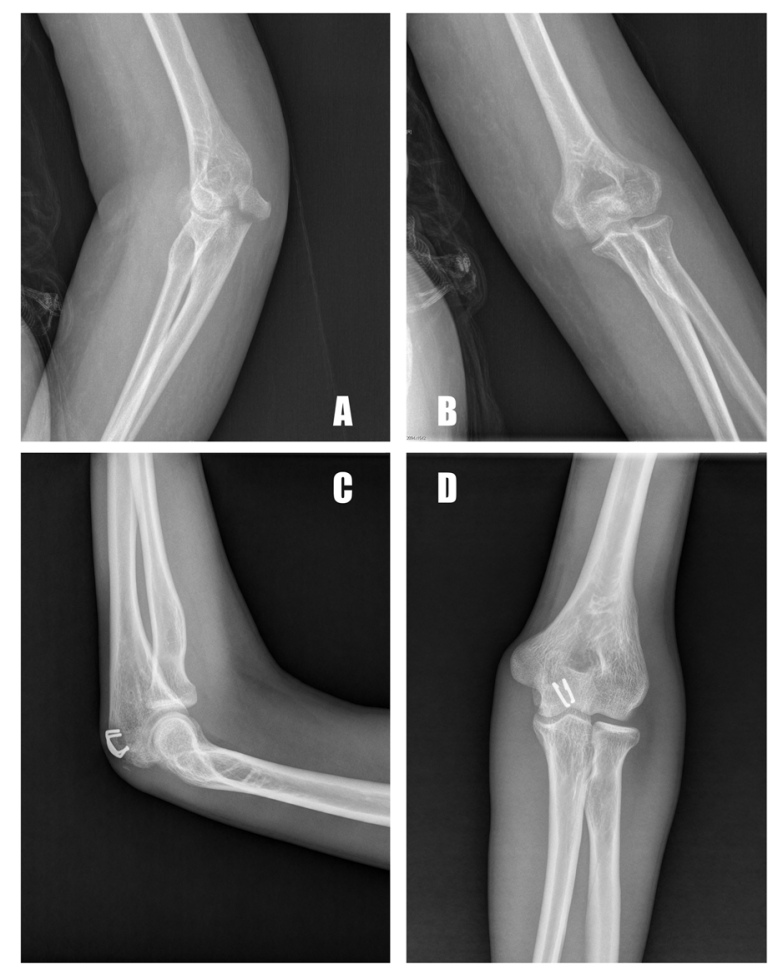

Fig. 4 A 38-year-old male patient with olecranon fracture caused by a fall onto his ankle $(\mathbf{a}, \mathbf{b})$. Fragments were reduced and fixed with the ASC. Ten months after the surgery, the radiographs showed a healed fracture and the ankle joint surface was anatomically reduced without any gap or step-off $(\mathbf{c}, \mathbf{d})$

produced by tension band fixation into compression forces at the articular surface, making the fracture site closer and accelerating the healing of the fracture [32]. Furthermore, TBW allows for less soft-tissue stripping, which contributes to less damage [33]. Compared with TBW, PF possesses the advantage of an increased stability [31] and is related to lower rates of hardware prominence [34]. Luksic et al. [25] reported that in the treatment of comminuted olecranon fractures a new technical tension plate combined with two Kirschner wires could provide adequate stability for early postoperative functional recovery, producing good clinical outcomes and increasing the fracture union rate [25]. However, hardware-related symptoms have been a common complication, with a rate of approximately 56 to $76.2 \%$, leading to a secondary operation for removal $[1$, 12]. Additionally, the excessive strip of periosteum and intraoperative damage of soft tissues will affect the healing of fractures.

Despite the lack of long-term rigorous controlled studies, our surgical team usually prefers the application of the ASCs for Mayo type II and type III olecranon fractures without nonunion or non-traumatic fractures when the patients tolerate the operation. The ASC used 


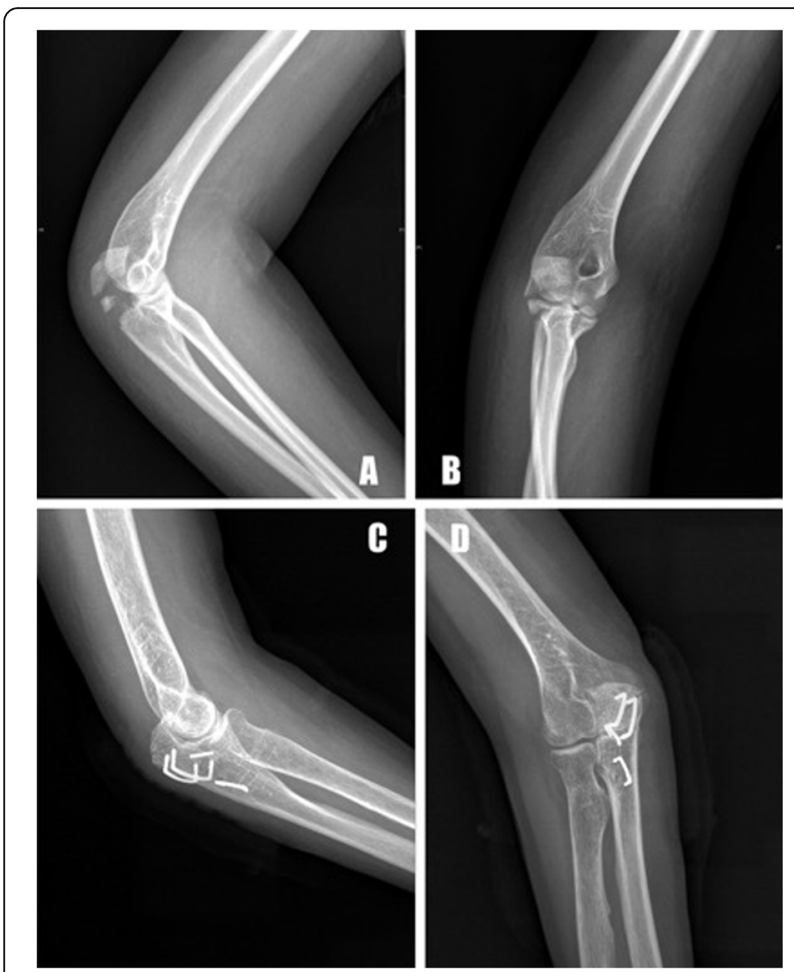

Fig. 5 A 55-year-old male patient with commuted olecranon fracture caused by a traffic accident $(\mathbf{a}, \mathbf{b})$. Fragments were reduced and fixed with the four ASCs. Eleven months after the surgery, the radiographs showed healed fractures, and the ankle joint surface was anatomically reduced without any gap or step-off $(\mathbf{c}, \mathbf{d})$

in this study is an industrial product into which the $\mathrm{Ni}$ $\mathrm{Ti}$ shape-memory alloy is incorporated. The ASC has the biocompatibility and corrosion resistance superiority of the Nitinol shape memory alloy and can transform its shape with temperature changes, improving the

Table 2 Preoperative and final follow-up clinical outcomes

\begin{tabular}{ll}
\hline Follow-up time, months (range) & $\mathbf{4 4}$ (31-56) \\
\hline Postoperative complications, $n$ & 2 \\
Prominent hardware & 1 \\
Infection & 0 \\
Arthritis & 5 \\
Loss of range of functional motion & 3 \\
Flexion $<128^{\circ}$ & 1 \\
Extension $<116^{\circ}$ & 1 \\
Pronation $<72^{\circ}$ & 0 \\
Supination $<72^{\circ}$ & 1 \\
Heterotopic Ossification & 0 \\
Nonunion & 0 \\
Nard failure & $8.6(2.1)$ \\
DASH scores (SD) & 92.5 (7.5) \\
MEP scores (SD)
\end{tabular}

intraoperative and postoperative outcomes. Although the ASC has been effectively applied to treat the humeral shaft, acetabular, and scaphoid waist fractures [19, 20, 35-37], no clinical study has been reported on its use in the treatment of olecranon fractures. Applying an optimal technique may not only reduce the postoperative complications but also decrease the need for secondary operations, particularly metal removal, and patients' discomfort. Compared with conventional techniques, the ASC may have several advantages. (1) Due to the limited space and thin skin at the olecranon, traditional implants will cause skin irritation and pain. Regardless of whether TBW and PF or other methods are used, the hardware removal rates are up to $77 \%$ and $76.2 \%$, respectively [1]. However, the ASC with a simple structure occupies less space and can thus only cause minimal skin irritation and pain when the elbow joint undergoes early movement, decreasing the removal rates. (2) Nonunion is also a complication that needs to be avoided, and in some patients, the interfragmentary compression is significant for union. The traditional compression that internal fixation produces is discontinuous, static, and passive, and similarly to TBW, it only produces compression when the elbow is extended between 30 and $120^{\circ}$ and against gravity [38], easily resulting in delayed union [39]. Instead, compression of the ASC derived from the compression arms in the device provides evenly distributed, continuous compression forces that can be transmitted across the fracture terminus, contributing to healing. (3) The ASC is manufactured using a Ni-Ti shape-memory alloy. Titanium and its alloys can become tightly integrated into the bone, which is a procedure that has been widely used in orthopedics [14]. Additionally, the ASC possesses a high strength and low modulus, which can effectively avoid the "stress shielding effect" [40]. (4) In clinical practice, surgeons prefer TBW for simple displaced olecranon fractures and plate fixation for displaced comminuted olecranon fractures [7]. However, when the fracture lines are irregular, the placement of fixators will be complex. Instead, the use of ASC is more flexible and widely applicable to diverse fracture lines. (5) As an important sports joint that is important for functional motion, the stability of the fixation depends mainly on whether early functional exercise can be achieved. We can adjust the number and size of the ASCs during the operation according to the needs of stability. Therefore, the patient can be encouraged to flex and extend the elbow joint earlier after the operation, which can explain the results of joint mobility of the patient in our study that was ideal. (6) The surgical procedure is also an important factor for choosing the treatment plan. The ASC technique is quite simple and only requires towel forceps and Kirschner wires for temporary fixation and an electric drill for drilling holes. 
When the ASC needs to be removed, it is treated with ice water to enhance its plasticity and then pulled out directly using tools. A simple procedure means a small amount of damage, a short operation time, and a low risk of vascular injury and blood loss.

However, several limitations should be highlighted: Due to the nature of the shape-memory alloy, the ASCs should be washed as needed with warm water for all subsequent procedures following implantation. Washing the implanted device with water at $<40{ }^{\circ} \mathrm{C}$ should be avoided because this may impede the fixation performance; in severe comminuted fractures, particularly in those with bone loss or subchondral fragments at the articular surface, initiating early movements after the ASCs osteosynthesis alone may cause failure. The ASCs may serve as an additional support to provide axial and angular stability based on the locking plate and screw fixation. Thus, the safety and stability of the application of the ASCs in bone-loss patients require further exploration. Additionally, before the study, we did not evaluate the patient's bone health in detail and excluded factors such as osteoporosis that affect fracture healing. Due to the number of included patients, no patient was aged older than 60 years, a finding that may not accurately evaluate the application of the ASCs in patients with on old olecranon fractures. Additionally, although we achieved relatively successful outcomes after the followup of 57 patients, the study is a single-case-series retrospective study with no comparative cohort in our study. Thus, a further prospective cohort study is warranted.

\section{Conclusion}

Accurate repair of the joint surface and absolute stability that allows the initiation of early joint motion are necessary for successful outcomes. Although our study was limited by the lack of a comparative group, the results of our series suggest reliable treatment outcomes. In the treatment of olecranon fractures, the ASC may not only serve as a favorable device for multi-fragmented fractures with rare hardware irritation but also provide a continuous compression to accelerate osseous healing, thereby aiding the restoration and permitting an early rehabilitation with a low incidence of postoperative complications.

\section{Supplementary information}

Supplementary information accompanies this paper at https://doi.org/10. 1186/s13018-020-01982-2.

Additional file 1: Video 1. this is the working principle of the ASC. The ASC was placed in $0-4^{\circ} \mathrm{C}$ ice water for cooling in advance and then the ASC will be so malleable that the arms can easily be unfolded using needle forceps. When $40-50{ }^{\circ} \mathrm{C}$ water was used to warm the device by injector, its memory mechanical functions was stimulated, the ASC returned to his original form, which can provide a continuous lateral compressive force.

\section{Abbreviations}

ASC: Arched shape-memory connector; TBW: Tension band wiring; PF: Plate fixation

\section{Acknowledgements}

None.

\section{Authors' contributions}

Shuogui Xu and Yuntong Zhang were responsible for the study design. Yan Xia and Zichen Hao were responsible for performing the clinical procedures. Lei Li and Demeng Xia were responsible for analyzing the data. Demeng Xia and Panyu Zhou were responsible for manuscript drafting. All authors have critically reviewed and approved the final manuscript.

\section{Funding}

This study was funded by the National Natural Science Foundation of China No. 81741111 and No. 81571887.

\section{Availability of data and materials}

We state that data will not be shared because all raw data were used to prepare the figures included in the article.

\section{Ethics approval and consent to participate}

This study was approved by the Committee on Ethics of Biomedicine Research of Changhai Hospital. All procedures involving human participants were conducted in accordance with the ethical standards of the institutional and/or national research committee and with the 1964 Declaration of Helsinki and its later amendments or comparable ethical standards. All patients signed informed consent forms prior to the study.

\section{Consent for publication}

Not applicable.

\section{Competing interests}

The authors declare that they have no competing interests.

\section{Author details}

${ }^{1}$ Department of Emergency, Changhai Hospital, the Naval Medical University, No.168, Changhai St, Shanghai 200433, People's Republic of China.

Department of Orthopaedics, Eastern Theater Naval Hospital, No. 98 Wenhua St, Zhoushan, Zhejiang 316000, People's Republic of China.

Received: 9 May 2020 Accepted: 23 September 2020

Published online: 02 October 2020

\section{References}

1. Wood T, Thomas K, Farrokhyar F, Ristevski B, Bhandari M, Petrisor B. A survey of current practices and preferences for internal fixation of displaced olecranon fractures. Can J Surg. 2015;58:250-6.

2. Powell AJ, Farhan-Alanie OM, Bryceland JK, Nunn T. The treatment of olecranon fractures in adults. Musculoskelet Surg. 2017;101:1-9.

3. Tarallo L, Mugnai R, Adani R, Capra F, Zambianchi F, Catani F. Simple and comminuted displaced olecranon fractures: a clinical comparison between tension band wiring and plate fixation techniques. Arch Orthop Trauma Surg. 2014;134:1107-14.

4. Horne JG, Tanzer TL. Olecranon fractures: a review of 100 cases. J Trauma. 1981;21:469-72.

5. Sheehan SE, Dyer GS, Sodickson AD, Patel KI, Khurana B. Traumatic elbow injuries: what the orthopedic surgeon wants to know. Radiographics. 2013; 33:869-88.

6. den Hamer A, Heusinkveld M, Traa W, et al. Current techniques for management of transverse displaced olecranon fractures. Muscles Ligaments Tendons J. 2015;5:129-40.

7. Ren YM, Qiao HY, Wei ZJ, et al. Efficacy and safety of tension band wiring versus plate fixation in olecranon fractures: a systematic review and metaanalysis. J Orthop Surg Res. 2016;11:137. 
8. Karlsson MK, Hasserius R, Besjakov J, Karlsson C, Josefsson PO. Comparison of tension-band and figure-of-eight wiring techniques for treatment of olecranon fractures. J Shoulder Elb Surg. 2002;11:377-82.

9. Saeed ZM, Trickett RW, Yewlett AD, Matthews TJ. Factors influencing K-wire migration in tension-band wiring of olecranon fractures. J Shoulder Elb Surg. 2014;23:1181-6.

10. Willinger L, Lucke M, Cronlein M, Sandmann GH, Biberthaler P, Siebenlist S Malpositioned olecranon fracture tension-band wiring results in proximal radioulnar synostosis. Eur J Med Res. 2015;20:87.

11. Fantry A, Sobel A, Capito N, et al. Biomechanical assessment of locking plate fixation of comminuted proximal olecranon fractures. J Orthop Trauma. 2018;32:e445-e50.

12. Buijze $G$, Kloen P. Clinical evaluation of locking compression plate fixation for comminuted olecranon fractures. J Bone Joint Surg Am. 2009;91:2416-20.

13. Hoh DJ, Hoh BL, Amar AP, Wang MY. Shape memory alloys: metallurgy, biocompatibility, and biomechanics for neurosurgical applications. Neurosurgery. 2009;64:199-214 discussion-5.

14. Navarro M, Michiardi A, Castano O, Planell JA. Biomaterials in orthopaedics. J R Soc Interface. 2008;5:1137-58.

15. Song $K$, Min T, Jung JY, Shin D, Nam Y. A superhydrophilic nitinol shape memory alloy with enhanced anti-biofouling and anti-corrosion properties. Biofouling. 2016;32:535-45.

16. Bhardwaj A, Gupta AK, Padisala SK, Poluri K. Characterization of mechanical and microstructural properties of constrained groove pressed nitinol shape memory alloy for biomedical applications. Mater Sci Eng C Mater Biol Appl. 2019;102:730-42

17. Witkowska J, Sowinska A, Czarnowska E, Plocinski T, Kaminski J, Wierzchon T. Hybrid a-CNH+TiO2+TiN-type surface layers produced on NiTi shape memory alloy for cardiovascular applications. Nanomedicine (London). 2017; 12:2233-44.

18. Takale AM, Chougule NK. Effect of wire electro discharge machining process parameters on surface integrity of Ti49.4Ni50.6 shape memory alloy for orthopedic implant application. Mater Sci Eng C Mater Biol Appl. 2019;97: 264-74.

19. Chen X, Liu P, Zhu X, Cao L, Zhang C, Su J. Design and application of nickel-titanium olecranon memory connector in treatment of olecranon fractures: a prospective randomized controlled trial. Int Orthop. 2013;37: 1099-105.

20. Sharma M, Sharma S. Comment on: shape memory Ni-Ti alloy swan-like bone connector for treatment of humeral shaft nonunion. Int Orthop. 2010; 34:1071.

21. Poggetti A, Rosati M, Castellini l, et al. Treatment of scaphoid waist nonunion using olecranon bone graft and Stryker Asnis micro cannulated screw: a retrospective study-80 case studies and 6 years of follow-up. J Wrist Surg. 2015;4:194-9.

22. Zhang Y, Zhao X, Tang Y, Zhang C, Xu S, Xie Y. Application of Ni-Ti alloy connector for the treatment of comminuted coronal plane supracondylarcondylar femoral fractures: a retrospective review of 21 patients. BMC Musculoskelet Disord. 2013;14:355.

23. Zhang Y, Zhao X, Tang Y, Zhang C, Xu S, Xie Y. Comparative study of comminuted posterior acetabular wall fracture treated with the acetabular tridimensional memory fixation system. Injury. 2014;45:725-31.

24. Lustenberger T, Leonardy R, Marzi I, Frank J. Outcome after surgical treatment of complex elbow fractures: a single-center follow-up study. Eur J Trauma Emerg Surg. 2019.

25. Luksic B, Juric I, Boschi V, Pogorelic Z, Bekavac J. Tension plate for treatment of olecranon fractures: new surgical technique and case series study. Can J Surg. 2015;58:24-30.

26. Erturer RE, Sever C, Sonmez MM, Ozcelik IB, Akman S, Ozturk I. Results of open reduction and plate osteosynthesis in comminuted fracture of the olecranon. J Shoulder Elb Surg. 2011;20:449-54.

27. Longo UG, Franceschi F, Loppini M, Maffulli N, Denaro V. Rating systems for evaluation of the elbow. Br Med Bull. 2008:87:131-61.

28. Wilkerson JA, Rosenwasser MP. Surgical techniques of olecranon fractures. J Hand Surg [Am]. 2014;39:1606-14.

29. Sun X, Yang GJ, Zhang L, Wang WL, Xie BJ. Treatment of patellar fractures with cable through the bone and Kirschner with a hole in the tail. China Journal of Orthopaedics \& Traumatology. 2015;28:603-5.

30. Chalidis BE, Sachinis NC, Samoladas EP, Dimitriou CG, Pournaras JD. Is tension band wiring technique the "gold standard" for the treatment of olecranon fractures? A long term functional outcome study J Orthop Surg Res. 2008;3:9.

31. Baecher N, Edwards S. Olecranon fractures. J Hand Surg [Am]. 2013;38: 593-604

32. Ling M, Zhan S, Jiang D, Hu H, Zhang C. Where should Kirschner wires be placed when fixing patella fracture with modified tension-band wiring? A finite element analysis. J Orthop Surg Res. 2019;14:14.

33. Yildiz C, Kurklu M, Ozkan $\mathrm{H}$, et al. AO tension band technique application in proximal humerus fractures. Eklem Hastalik Cerrahisi. 2010;21:62-7.

34. Munoz-Mahamud E, Fernandez-Valencia JA, Riba J. Plate osteosynthesis for severe olecranon fractures. J Orthop Surg (Hong Kong). 2010;18:80-4.

35. Cao LH, Xu SG, Wu YL, Zhang CC. Treatment of nonunion of scaphoid waist with Ni-Ti shape-memory alloy connector and iliac bone graft. J Mater Eng Perform. 2011;20:629-31

36. Liu X, Xu S, Zhang C, Su J, Yu B. Application of a shape-memory alloy internal fixator for treatment of acetabular fractures with a follow-up of two to nine years in China. Int Orthop. 2010;34:1033-40.

37. Xu S-G, Zhang C-C, Wu Y-L, Fu Q-G. Swan-like memory compressive connector. J Mater Eng Perform. 2011;20:139-42.

38. Brink PR, Windolf $M$, de Boer P, Brianza S, Braunstein V, Schwieger K. Tension band wiring of the olecranon: is it really a dynamic principle of osteosynthesis? Injury. 2013;44:518-22.

39. Ates $Y$, Atlihan D, Yildirim H. Current concepts in the treatment of fractures of the radial head, the olecranon and the coronoid. J Bone Joint Surg Am. 1996;78:969

40. Xin-wei L, Shuo-gui X, Chun-cai Z, Qing-ge F, Pan-feng W. Biomechanical study of posterior wall acetabular fracture fixation using acetabular tridimensional memory alloy-fixation system. Clin Biomech (Bristol, Avon). 2010;25:312-7.

\section{Publisher's Note}

Springer Nature remains neutral with regard to jurisdictional claims in published maps and institutional affiliations.
Ready to submit your research? Choose BMC and benefit from:

- fast, convenient online submission

- thorough peer review by experienced researchers in your field

- rapid publication on acceptance

- support for research data, including large and complex data types

- gold Open Access which fosters wider collaboration and increased citations

- maximum visibility for your research: over $100 \mathrm{M}$ website views per year

At BMC, research is always in progress.

Learn more biomedcentral.com/submissions 